Tailor Made Concrete Structures - Walraven \& Stoelhorst (eds)

C 2008 Taylor \& Francis Group, London, ISBN 978-0-415-47535-8

\title{
Detail design of the MPU Heavy Lifter
}

\author{
H. Ludescher \& S.A. Haugerud \\ Olav Olsen as, Oslo, Norway \\ M. Fernández Ruiz \\ Ecole Polytechnique Fédérale de Lausanne
}

\begin{abstract}
This paper gives insight into detail design of the MPU Heavy Lifter. The innovative structure is developed for offshore heavy lifting operations like removing or installing platforms. Its hull is composed of highly reinforced and prestressed lightweight concrete forming slabs and walls with thicknesses between $0.3 \mathrm{~m}$ and $0.9 \mathrm{~m}$. Information is provided on the design procedure, on the basis of design and on the design of B- and D-regions. Structural analysis is based on finite element analysis using shell elements. For design and verification of concrete sections the results are post-processed with specially developed software. For D-regions, truss and stress-field modelling supported by specialised finite element analysis is applied. The applicability of these design methods is verified with a series of small and large scale tests.
\end{abstract}

\section{INTRODUCTION}

The MPU Heavy Lifter is a large lightweight concrete structure that has been conceived to perform heavy offshore lifting operations (Figure 1). Overall concept and main features of the vessel are described elsewhere in the proceedings (Landbø et al. 2008). This paper focuses on the structural design of the concrete hull including general design procedure and premises, especially those related to the application of lightweight aggregate concrete.

The particular challenges in designing the concrete hull of the MPU Heavy Lifter were:

- complex loading,

- stringent weight restrictions,

- application of a lightweight concrete for which limited field experience exists,

- complex and highly optimized structure.

\section{DESIGN PROCEDURE}

Based on extensive experience in designing offshore concrete structures, the design process is largely unified and computerised. Guided by a common design basis and supported by a "global" FE-analysis, several design groups work in parallel to meet strict deadlines for construction. Efficiency is achieved by high specialisation on tasks like project management, structural analysis, post-processing and drawing production. Drawing production progresses in steps

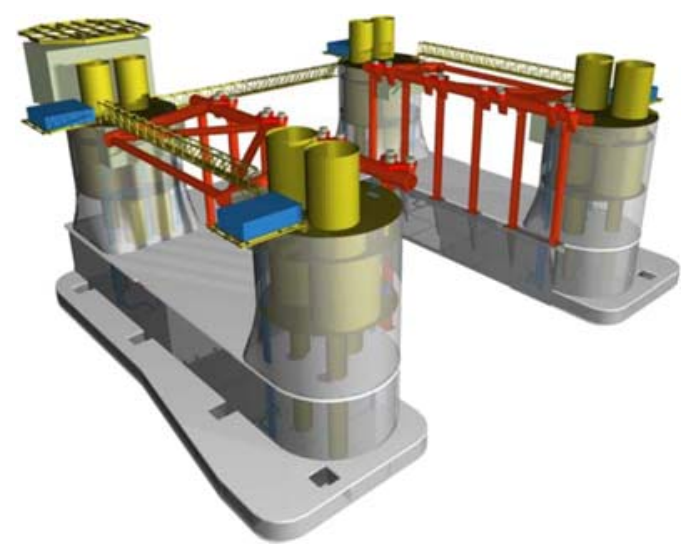

Figure 1. 3D model of MPU Heavy Lifter.

with increasing accuracy where each step is subjected to quality control.

The major difference to other large projects probably is the complex loading. During construction and operation in marine environment, the structure experiences various distinctly different load phases. For each phase, numerous criteria have to be verified in each element. As a consequence, thousands of design combinations are assembled and verified.

Even before the structural analysis produces results, the design groups start to develop the reinforcement system in function of the construction method. Critical 
regions are identified and advanced analyses are initiated. In the case of the Heavy Lifter, about 50 persons had less than a year to produce about 1000 documents. For the interface coordination, a 3D model is used that puts all structural elements in the right context and allows detecting conflicts.

\section{BASIS OF DESIGN}

The main reference for detail design, materials and construction of the entire vessel is the Lloyd's provisions for classification (Lloyd's 1996). Design and verification related to the concrete hull are carried out in accordance with DNV Regulations (e.g. DNVOS-C101 2004) and Norwegian Standards. Notably the concrete hull is designed in accordance with the structural design code NS 3473.E 2003 which covers the application of lightweight aggregate concrete structures.

\subsection{Material properties}

In order to minimize the deadweight to displacement ratio of the vessel (maximisation of lifting capacity), an all lightweight aggregate concrete (ALWAC) has been chosen for the concrete hull. Only in small, highly stressed regions normal density concrete (C55) is applied. The high performance ALWAC is of grade LC35/38 and has an in situ density of less than $1600 \mathrm{~kg} / \mathrm{m}^{3}$. The strength and deformation properties for the ALWAC are based on density dependent modification of the properties for normal density concrete of the same strength class. The reduction factors for E-modulus $(\rho / 2200)^{2}$ and tensile strength $0.85 \cdot(0.15+\rho / 2200)$ were based on a oven dry density of $\rho 1350 \mathrm{~kg} / \mathrm{m}^{3}$. The standard design properties according to NS 3473.E 2003 obtained for the ALWAC in question are given in Table 1.

Steel grade for ordinary, deformed reinforcement is B500C. For post-tensioning bonded multi-strand tendons BS 5896 Super (1600/1860) are employed.

\subsection{Design criteria and provisions}

The most significant design criteria for the hull are those relevant to the use of the ALWAC. The

Table 1. Concrete properties.

\begin{tabular}{ll}
\hline Grade & LC $35 / 38$ \\
\hline In situ density, $\rho_{c}$ & $1600 \mathrm{~kg} / \mathrm{m}^{3}$ \\
Nominal compressive strength, $f_{c n}$ & $27.3 \mathrm{MPa}$ \\
ULS compressive strength, $f_{c d}$ & $21.8 \mathrm{MPa}$ \\
ULS tensile strength, $f_{t d}$ & $0.91 \mathrm{MPa}$ \\
Young's modulus, $E_{c k}$ & $10.4 \mathrm{GPa}$ \\
Poisson's ratio, $v$ & 0.2 \\
\hline
\end{tabular}

design provisions in NS 3473.E 2003 for this high strength/low density ALWAC could be applied with little need for adjustments, as their adequacy was largely demonstrated through the research programmes Lightcon and EuroLightCon (EuroLightCon 1998).

In order to provide robustness and to ease the construction process, project specific 'standardization' of reinforcement bending, splicing and placing is established in a reinforcement detailing manual. It is based on the Norwegian standard NS 3473.E 2003 and considers the specificities of lightweight concrete, in particular the low concrete tensile strength and the relative brittleness.

The relative low tensile strength requires considerable anchorage and lap lengths as well as increased bending radii. In order to avoid lap lengths of up to $2.4 \mathrm{~m}$, mechanical coupling was used as far as possible. In some regions, stirrups were used for confinement in order to limit anchorage and lap lengths. Especially in joints, headed reinforcement was used consistently.

The brittleness of lightweight concrete required particular attention to possible spalling of the concrete cover. This problem was tackled by careful reinforcement detailing. Main issues are maximum bar diameter, permissible bending radii, bundling of bars and tensile splitting reinforcement.

Minimum reinforcement above the waterline is $1 \varnothing 25 \mathrm{mmc} 200 \mathrm{~mm}\left(2454 \mathrm{~mm}^{2} / \mathrm{m}\right)$. Below the lower waterline, in structural members subjected to differential water pressure, this intensity is at least doubled. A minimum amount of shear reinforcement $\left(1400 \mathrm{~mm}^{2} / \mathrm{m}^{2}\right)$ was provided in all structural members in order to improve ductility and prevent delamination.

\subsection{Testing}

Although high performance lightweight aggregate concretes with material and production properties adequate for use in concrete floating structures were developed during the 1990ies, the application of an ALWAC of density class D1,4 in a complex offshore structure is so far unique. Due to the lack of relevant test evidence and limited previous real-life experience, a comprehensive laboratory test program has been conducted to investigate and document concrete properties and structural performance:

- concrete testing (stress-strain diagram, density, uniaxial tensile strength, creep and shrinkage)

- welding for load bearing lap-splicing

- anchorage of conventional reinforcement (pull-out of headed reinforcement, push-out of headed studs for embedment plates)

- anchorage of post-tensioned reinforcement (load transfer at anchorages, pull-out of strands in grout, strand anchors)

- full-scale test of plate - wall corner 
The concrete mix design involved a series of trial mixes, both in laboratory (at SINTEF, Norway) and in full scale at the batching plant in Rotterdam. The work in laboratory led to the development of a mix that met the workability and performance criteria relevant for marine structures. In order to reduce the heat of hydratation implying the risk of cracking due to thermal shrinkage a separate mix dedicated hot weather concreting was developed. At the plant it was necessary to optimise the mixing procedure as well as the addition of water in function of the aggregate humidity. Finally the produced concrete performed well in excess of the postulated criteria.

Early tests of the load transfer at post-tensioning anchorages indicated that the concrete was sensitive to concentrated loading. Confinement had a limited effect in increasing the effective concrete compressive strength because crushing of lightweight aggregate became governing at high stress levels. For this reason, the concentrated anchorage of rebars by the means of T-heads was tested. Both, pullout tests on T-headed bars and push-out tests on headed bolts were carried out (at EPFL, Switzerland). The tests showed favourable results with ductile failure of the reinforcement limiting the capacity.

A full-scale test was carried out on a frame corner detail (see Figure 2 and details in section 5) that confirmed bending as the governing failure mode. Good performance was observed for the detail with the anchorage of bundled T-headed bars in a tensiontension-compression node (Figure 9). The structural behaviour of the cross section was very ductile despite the brittleness of the material and the high reinforcement ratio. Detailing of the joint proved to be effective and no major deformations and weakening of the nodal region were registered. The test confirmed that design methods like truss modelling are applicable despite the brittleness of the material.
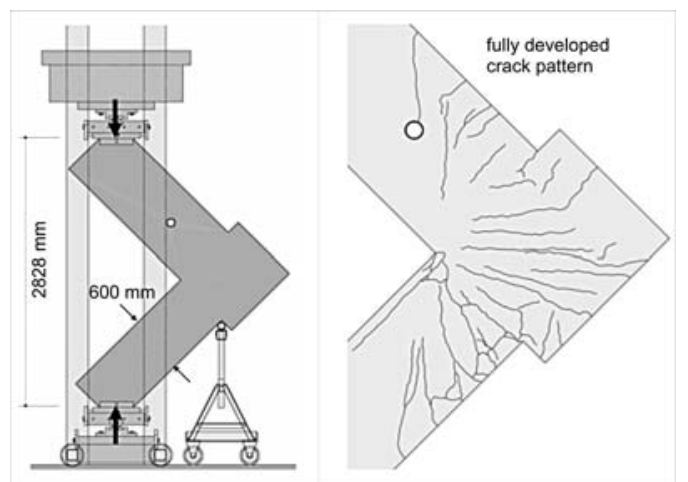

Figure 2. Full scale corner test (testing at EPFL, Switzerland).

\subsection{Structural analysis of concrete hull}

The structural analysis of the concrete hull is based on a "global" finite element model built of 8-node plane shell elements. The mesh with its approximately 400000 degrees of freedom is sufficiently fine to provide cross sectional forces for local bending moments and shear forces at joints. It is used for two types of analyses:

- standard, linear elastic analysis

- advanced, non-linear analysis considering local decrease in stiffness due to concrete cracking.

The non-linear analysis is employed to predict the response for extreme situations, e.g. the action of a 100 year summer storm wave hitting the vessel from the most unfavourable direction during transit with a heavy cargo. In the analysis, variable loads are increased stepwise and the local response obtained from post-processing is used to update the stiffness matrix.

For the majority of design combinations, standard linear elastic analysis is used which allows for the superposition of action effects. For several details not covered by the "global" analysis, local analyses are used.

\subsection{Load modelling}

The load phases defined in the design basis include "Flooding of Dock", "maximum draft", "offshore lift", "transit with wave" and accidental situations like flooding of a compartment, ship impact or dropped objects. For each of the load phases, design combinations are generated that reproduce the governing section forces in the critical elements. All in all more than 3000 design combinations are used. They are constituted of various types of load cases that are classified into (see Table 2).

More than 700 single load cases have been defined. In order to ease design and verification, each load case only includes few forces in one direction. The post-tensioning of the Base slab, for example, is

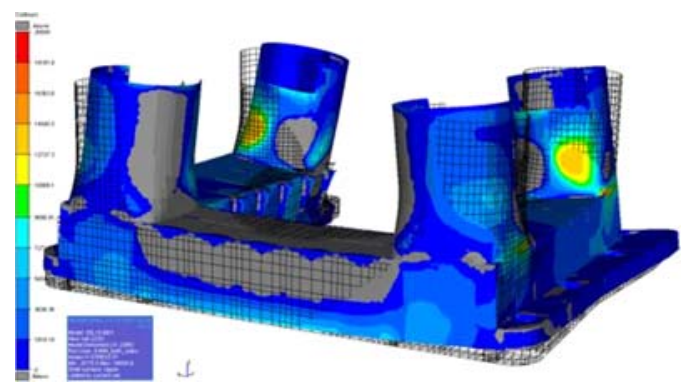

Figure 3. FE-model subjected to horizontal forces introduced by lifting frame. 
Table 2. Classification of load cases, load factors (according to DNV-OS-C101 2004).

\begin{tabular}{ll}
\hline Category & ULS load factor \\
\hline Self weight, flush tanks & 1.2 \\
Post-tensioning & 0.9 or 1.1 \\
Ballast, buoyancy material in brim & 1.2 \\
Life load, payload (contact force) & 1.3 \\
Static water pressure & 1.2 \\
Dynamic water pressure (wave) & 1.2 \\
\hline
\end{tabular}

For service limit state (SLS) and accidental limit state (ALS) generally a load factor of 1.0 is used.

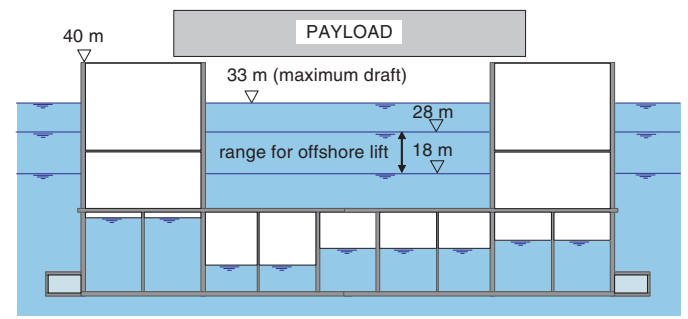

Figure 4. Draft for load phase "offshore lift" and "max. draft".

modelled with 35 load cases. Each contains selfequilibrating forces that represent the effect of tendons anchored in the same place. A typical design combination includes 100 to 200 load cases. As the vessel is floating, the structure has no supports constituting the external boundary conditions. Instead, the resultant of all load cases has to be zero. Weights are balanced by buoyancy and proper ballast levels whereas horizontal forces causing accelerations are in equilibrium with inertial forces.

The most important load phases for design are "maximum draft" and "transit with wave". "Maximum draft" is defined as $33 \mathrm{~m}$ (Figure 4), i.e. the vessel is verified for a characteristic water pressure of $1.2 .33 \mathrm{~m}$ at ULS. The static water pressure for this phase slightly exceeds the values for the phase "transit with wave" in most areas of the hull. Design waves hitting the vessel in a diagonal direction cause maximum opening or closing of the U-shaped vessel. The corresponding forces are governing design of the inner corners in the base and top slab.

\section{SECTIONAL DESIGN}

For sectional design, the results of the structural analysis are processed with a tailor made design tool. The program called "ShellDesign" uses the stresses in the
Gauss points of the finite elements in order to integrate the section forces, to determine the required reinforcement and to perform all code checking. The section forces are divided into

- membrane forces: axial forces and in-plane shear

- bending moments and drilling moment

- transverse shear forces

Membrane forces and bending moments are used to determine or verify the cross section thickness as well as the main reinforcement (ULS) or stress level as well as crack width (SLS). Design for transverse shear (ULS) is based on the "equivalent beam" approach, a method commonly adopted for design of concrete offshore structures. In the case of submerged sections, water pressure in cracks is accounted for. At joints, the governing section forces are obtained by extrapolation from adjacent points. For verification and drawing production, several forms of graphical output are provided. This made it possible to efficiently process the results of the more than 90000 Gauss points and extrapolation points.

Slabs and walls are typically subdivided into panels of about $10 \mathrm{~m}$ times $10 \mathrm{~m}$. The thickness of the base slab generally is $0.7 \mathrm{~m}$, apart from highly stressed regions with $0.8 \mathrm{~m}$ thickness. The brim base slab is $0.4 \mathrm{~m}$ thick because it does not have to resist to differential water pressure. The wall thickness varies between $0.3 \mathrm{~m}$ and $0.9 \mathrm{~m}$ (Figure 6) and the column shells are $0.4 \mathrm{~m}$ to $0.8 \mathrm{~m}$ thick (Figure 8 ).

Maximum reinforcement intensities are usually found at the joints connecting a panel to the adjacent slab and walls. Depending on the location in the structure and on the loading situation, either "global" membrane forces or "local" bending moments are governing the main reinforcement. In the base slab, the minimum reinforcement consists of $1 ø 32 \mathrm{~mm}$ centre spacing $\mathrm{c}=200 \mathrm{~mm}\left(4021 \mathrm{~mm}^{2} / \mathrm{m}\right)$ in each of the four layers $(\mathrm{x}$ - and $\mathrm{y}$-direction in top and bottom face). The maximum reinforcement ratio is found at the inner corner of the Bottom slab (Figure 5), where ten layers of $2 \varnothing 32 \mathrm{c} 200$ and two layers of posttensioning cables are placed (Figure 7). Stirrup intensity ranges between $1 ø 12 \mathrm{c} 400 \mathrm{c} 400\left(1414 \mathrm{~mm}^{2} / \mathrm{m}^{2}\right.$, thin walls $)$ and $1 \varnothing 20 \mathrm{c} 200 \mathrm{c} 200\left(7855 \mathrm{~mm}^{2} / \mathrm{m}^{2}\right.$, slabs towards supports).

Tendons for post-tensioning consist of 12 and 19 strands cables that are typically spaced $0.8 \mathrm{~m}$. For the active anchorage, large plates are used that allow avoiding spirals as bursting reinforcement. For the passive anchorage, plates (in block-outs or blisters), loops or strand anchorages are used. Post tensioning is applied in the direction of the pontoons and towards their junctions also in the transverse direction. The columns include vertical post-tensioning. The level of compression due to post-tensioning typically attains -4 to $-5 \mathrm{MPa}$ (Figure 5). 


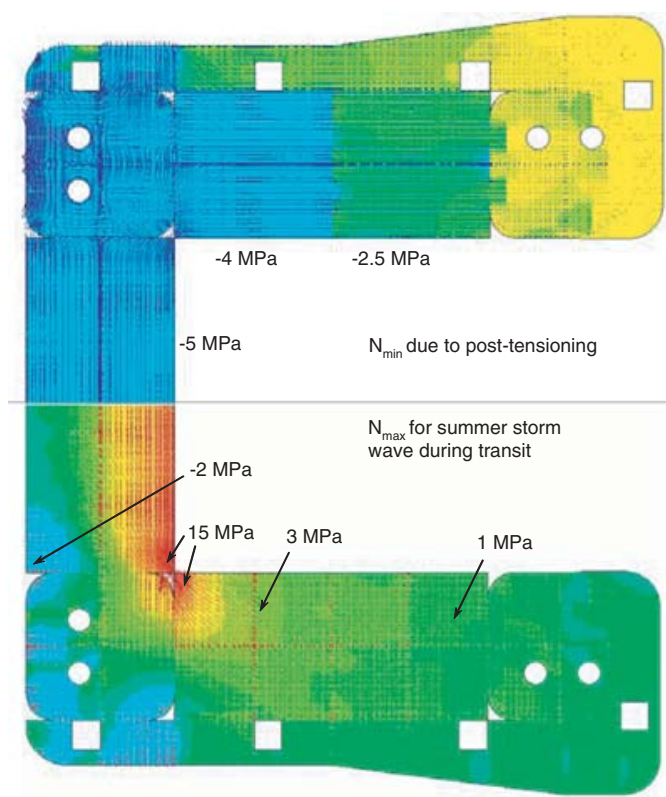

Figure 5. Stress level in Base slab due to post-tensioning (top) and due to summer storm wave during transit (elastic analyses).

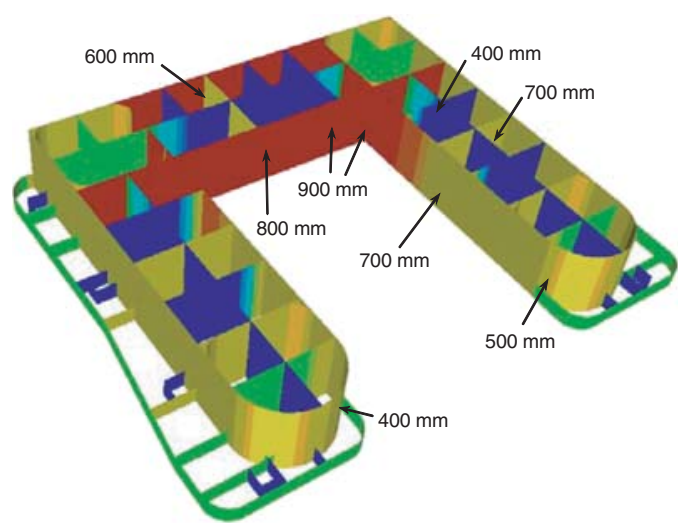

Figure 6. Wall thicknesses.

Due to their complex geometry, the columns are particularly challenging for construction. Starting with a close to quadratic footprint, the horizontal crosssection is gradually altered into a circular shape. In the majority of the shell, the thickness varies continuously. At their top and $10 \mathrm{~m}$ above the Top slab they have watertight steel decks which are connected to the concrete shell by the means of embedment plates (see Figure 1). Loading of the pivoted lifting frames causes high horizontal forces which the columns transfer from the lifting frame support to the top slab. This causes

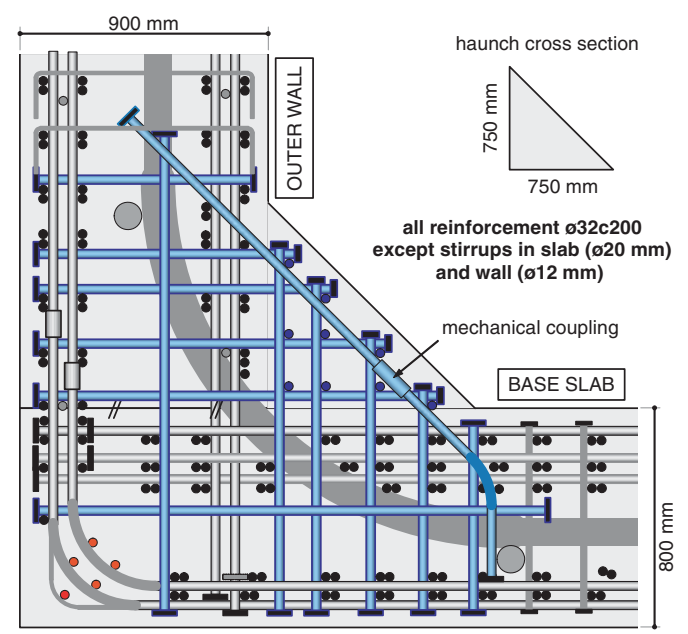

Figure 7. Detailing in corner with maximum reinforcement ratio.

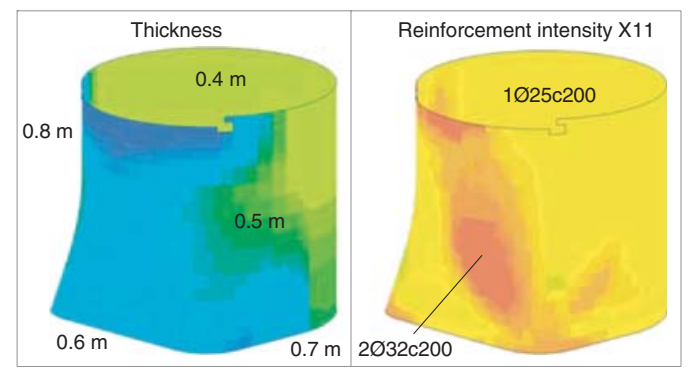

Figure 8. Column design $(\mathrm{X} 11=$ outer, horizontal bars $)$.

high in plane shear below the lifting frame support. Consequently, the inner column face has a thickness between $600 \mathrm{~mm}$ and $800 \mathrm{~mm}$ whereas the thickness of the opposite face varies between $500 \mathrm{~mm}$ and $400 \mathrm{~mm}$ (Figure 8). The reinforcement ratios correspond more or less to the thickness.

\section{DESIGN OF D-REGIONS}

Whereas sectional design generally allows for a precise determination of the required reinforcement ratios, D-region design is used to determine rebar anchorage and stress transfer in discontinuity regions. These include joints and other geometrical and statical discontinuities like post-tensioning anchorages or embedded items. The focus in D-region design is on appropriate reinforcement detailing. For this purpose, qualitative truss models are developed. Detailed models like quantitative truss/stress-field models or FE models are only applied in the case of high stresses and difficult reinforcement detailing. 


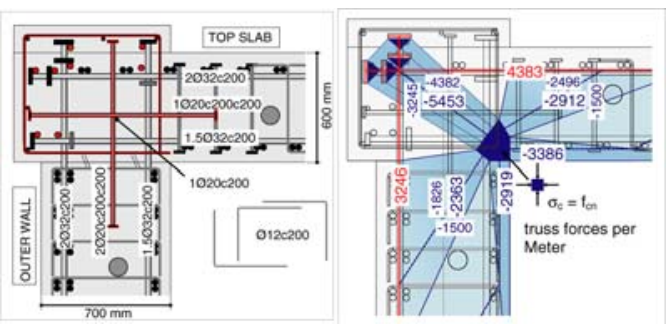

Figure 9. Joint Top slab - outer wall with stress-field model for closing moment.

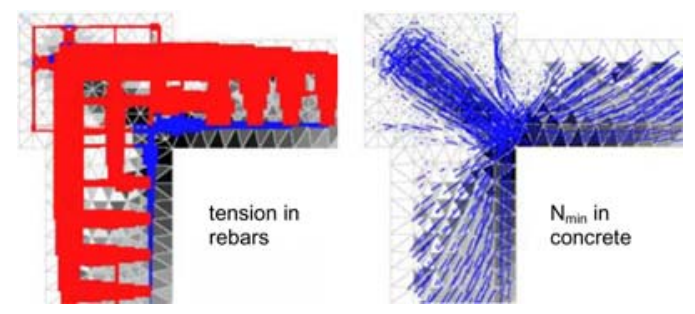

Figure 10. Analysis based on continuous stress fields.

For a systematic design, D-regions are grouped according to their geometry and loading situations. In addition, sectional design is used to identify highly stressed regions where reinforcement detailing is critical. An important example of a D-region is the L-joint between the Top slab and outer walls (Figure 9). It extends over about $260 \mathrm{~m}$ along the edge of the top slab. Water pressure at maximum draft results in high closing moments in the joint. Heavy lifting causes torsion and bending of the pontoons acting as box girders which results in high in-plane shear. For the anchorage of the main reinforcement in the joint, T-heads are used exclusively. In order to verify whether the concrete is able to withstand the stresses from bundles of $2 ø 32 \mathrm{~mm}$ T-headed bars, a full scale test was carried out (Figure 2).

For the optimisation of the reinforcement detailing, FE modelling on the basis of continuous stress fields (Fernández Ruiz et al. 2007) has been particularly useful. Compared to simple truss/stress-field models computed by hand, the FEA simplifies the consideration of all types of reinforcement in the region and allows for a better quantification of their benefit. The results of the analysis of the joint in Figure 9 are shown in Figure 10. It can be noted that a good agreement to hand-made (discontinuous) stress fields is obtained.

Maximum closing moments due to high water pressure led to strengthening of several joints with haunches. Figure 7 shows the example of a joint with a haunch that allows for the installation of curved

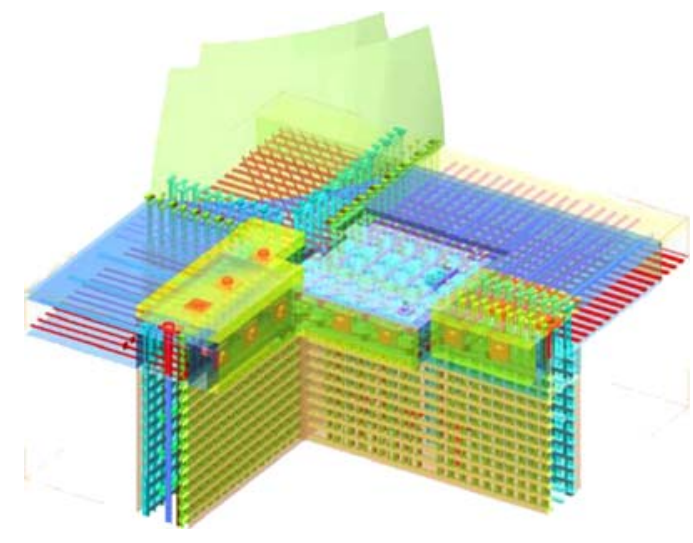

Figure 11. 3D model of inner corner in Top slab.

post-tensioning cables. This solution made it possible to avoid a series of post-tensioning anchorages. The low bending radius required installation of heavy reinforcement in the haunch. Due to the absence of significant opening moments, the diagonal haunch reinforcement is kept relatively simple.

\section{CONSTRUCTABILITY}

Good constructability was given high priority and all solutions were discussed in advance with construction specialists. In complicated regions, 3D models were generated in order to detect possible conflicts (Figure 11). The choice of structural solutions was delimited by the construction method applied for the respective element:

- Base slab and top slab were each cast in four legs of about $800 \mathrm{~m}^{3}$.

- The walls were constructed with climbing formwork extending over a fourth of the wall height.

- For the columns, slip-forming is used.

\section{CONCLUSION}

Detail engineering of the MPU Heavy Lifter was faced by numerous challenges that required high commitment and employment of all possibilities.

- Sophisticated structural analysis was used to determine the response expected during offshore lifting.

- Adequate structural capacity in extreme situations was verified using non-linear analysis that enabled to consider concrete cracking.

- The innovative application of lightweight concrete was accompanied by extensive testing to confirm design assumptions. 


\section{REFERENCES}

Lloyd's 1996. Lloyd's Register of Shipping: Rules and Regulations for Mobile Offshore Units.

DNV-OS-C101 2004. Offshore Standard DNV-OS-C10

Design of Offshore Steel Structures, General (LRFD Method). Det Norske Veritas.

NS 3473.E:2003. Design of concrete structures, Design- and detailing rules. 6th edition Sep. 2003, Norges Standardiseringsforbund.
EuroLightCon 1998. LWAC Material properties, State-ofthe-Art. Document BE96-3942/R2, Brite EuRam III, European Union.

Fernández Ruiz M. \& Muttoni A. 2007. On the Development of Suitable Stress Fields for Structural Concrete, ACI, Structural Journal, Vol. 104 n $^{\circ} 4$, pp. 495-502, Farmington Hills, USA.

LandbøT., Holm E.B., Ludescher H. 2008. MPU Heavy Lifter - a lightweight concrete vessel for heavy offshore lifting operations, proceedings to fib 2008 Amsterdam. 
